\section{DE MARIANA ALCOFORADO A LAS TRES MARÍAS, UN CAMINO DE CORAJE Y RESISTENCIA A PARTIR DE LA PALABRA}

FROM MARIANA ALCOFORADO TO “LAS TRES MARÍAS”, A WAY OF BRAVERY AND RESISTANCE THROUGH THE SPEECH

María de Lourdes Pereira Universitat de les Illes Baleares

Resumen:

Abstract:

Tras varias décadas del régimen de Salazar, After several decades of Salazar's regime, Portugal se encuentra en un período de Portugal is in a period of social unestability desorden social. Pocos años más tarde, surge Few years later, the project called "las Tres el proyecto llamado "las Tres Marías", dando Marías" came up, giving way to a feminist paso a un liberalismo feminista en el que se liberalism in which women were expected to esperaba que las mujeres tomasen conciencia become aware of their condition, regardless of de su condición independientemente de su their social status. This movement was born de su condin de las Nuevas Cartas Portuguesas, y obtuvo achieved a great support from abroad. de las Nuevas Cartas Portuguc
gran apoyo en el extranjero.

Palabras claves:

\section{KEY WORD:}

María Alcoforado, "las Tres Marías", woman.

María Alcoforado, “las Tres Marías”, mujer.
Las más de cuatro décadas de régimen salazarista dejaron en la sociedad portuguesa una impronta demasiado acentuada. Las señales más notorias se exteriorizan en una sociedad alimentada por un sistema dictatorial controlador y represivo que tendría su repercusión en la economía, pero sobretodo en la educación y en la cultura, ya que ésta se convirtió, una vez más, en un eficiente, e incluso sutil, modo de inspección y dominio del pueblo, y una de las medidas más "eficientes" surgió, indudablemente, con la creación de la Mocidade Portuguesa. Desde 1936 los jóvenes portugueses, de los siete a los catorce años, tenían por obligatoriedad apuntarse a la organización cuyos objetivos eran formar el carácter de los hombres de futuro, sin olvidar su robustez física, y fortalecerles en los principios morales y en el amor a la Patria. En 1937 fue creada el ala femenina, bajo la insignia de Mocidade Portuguesa Feminina, la cual tenía por objetivo educar a la mujer para lo que la sociedad esperaba de ella; ser una buena esposa, una buena ama de casa y una buena madre. En resumen, la filosofía social y cultural del régimen se ajustaba a la célebre tríade de "Dios, Patria y Familia", pero una fe y un amor que el régimen se encargaba de "enseñar" sin que hubiera espacio para la reflexión o el descubrimiento de los sentimientos o emociones; si en algún momento éstos se manifestaran ya se encargaría la tutela estatal de intervenir mediante la censura o la represión.

Después de más de cuatro décadas de régimen salazarista, la sociedad portuguesa agonizaba ya por todos sus poros. La represión y la dictadura no sólo marcaban las pautas de una conducta represiva sino que además estrangulaban la existencia de un pueblo condenado por una guerra que, según el régimen, no había existido nunca, aunque se le llegó a destinar un cuarenta por ciento del presupuesto general del estado, obligando a escatimar los gastos en otras partidas como eran la educación, la cultura o el bienestar social. Aun así, con el desarrollo de los acontecimientos el régimen se va desgastando, hasta que el día tres de agosto de 1960 el sillón donde Salazar se apoyaba se rompe, impidiendo al estadista volver a reposar en tan cómodo asiento.

En su lugar quedará el hombre de confianza, Marcelo Caetano quien, al sustituir a Salazar, que morirá en julio del 70, promete la llegada de una nueva primavera Las nubes tardarán aún en disiparse del horizonte luso pero, tal vez por esa nueva esperanza, o por simple cansancio, empiezan a alzarse voces de protesta contra la realidad nacional que emanaban, principalmente, del mundo de la cultura, voces que insistían en luchar, tanto en Portugal como en el exilio, contra un régimen que había empezado a dar muestras de extenuación a finales de la década de los 60. Tal como el régimen sabía, la cultura y la educación constituían una seria amenaza social, pero la represión, a par del terror, despertaba cada vez más la resistencia y el coraje de aquellos que tenían en la palabra su único poder. Se escuchan entonces los gritos de escritores, cantautores, pero también de aquellos a quienes llegaban sus mensajes, poniéndose 
en marcha una lucha sin tregua. De entre esos esfuerzos surge el proyecto que sería conocido como el de las Tres Marias, el cual se tornará en un marco revolucionario de la condición femenina, en Portugal y también en el extranjero, y que supo mantener su protagonismo a lo largo de todas estas décadas.

Corría el año de 1971 cuando Maria Isabel Barreno, Maria Teresa Horta y Maria Velho da Costa, tres amigas dadas a las letras, dos de ellas con obra ya publicada, deciden reunirse y dar inicio a un proyecto que preveía desestabilizar los sólidos y profundos cimientos de esa sociedad conservadora, clasista, y profundamente pasiva que el régimen había edificado a partir de sólidos apoyos como eran la economía, la religión y la cultura. Las tres Marías, suspirando por esa primavera que tardaba en llegar, proyectan una obra polémica que marcaría para siempre la historia de la literatura portuguesa y que saldrá a la luz en la primavera de 1972 pero, por el peligro que obras como estas representaban para la estabilidad de una sociedad como la portuguesa, el libro fue de inmediato prohibido por el gobierno portugués, siendo confiscados todos los ejemplares y detenidas las autoras bajo la acusación de abuso de la libertad de prensa y atentado a la moral pública(Barreno et allí 1974: 7). Poco más de un año después de su captura en Portugal, la militancia de la palabra de estas tres mujeres conquista Francia, el bastión del liberalismo feminista, por lo que la publicación de las Nuevas Cartas Portuguesas por las Edicións du Seuil constituyó un hito importante en la lucha de las tres Marías dado que, como apuntan Evelyne le Garrec y Monique Wittig en el prefacio a la edición francesa "au Portugal elle durait déjà depuis un an sans que personne en sache rien, ni dans ce pays où la presse, soumise à la censure, restait silencieuse, ni à l'etranger ." (Barreno et alli 1974: 8). A pesar de este silencio, hay ecos que salen del grito lanzado por las tres Marías que llegan a cruzar el Atlántico e incluso el mismo Times Magazine envía a Portugal un periodista para entrevistar a las autoras, en las mismas fechas en que estas eran juzgadas por ofensas a la moral pública portuguesa.

El proceso instaurado por las autoridades contra las autoras tuvo inicio en octubre de 1972 y sería dado por concluido en abril de 1974, con la caída del antiguo régimen. A lo largo de esos años las autoras fueron reuniendo apoyos que llegaban principalmente del extranjero, puesto que en el país era difícil que la gente expresara públicamente su apoyo frente a la represión y censura instaladas. En abril de 1974, con la llegada de la democracia de la mano de los capitanes de abril, el caso es definitivamente archivado y el juez les anima a que sigan escribiendo, diciéndoles que habían producido una obra de mucha calidad. A pesar de los cambios acaecidos, el peso de cuatro décadas de educación salazarista no se revelaba propicio a la aceptación, por parte de la sociedad, de una obra como ésta, por lo que, todavía hoy, no es fácil encontrar un ejemplar en las librerías portuguesas, a pesar del papel que estas cartas siguen ocupando en el panorama literario nacional e internacional y de que la actividad literaria de las autoras haya proseguido a lo largo de las décadas, aunque por separado.

Como proyecto colectivo, Nuevas Cartas Portuguesas surge desde el inicio bajo una serie de máscaras que, en vez de esconder, lo que hacen es disfrazar la realidad, pidiendo a gritos la intervención del espectador para que, a partir de un juego de complicidades, pueda desvendar el verdadero rostro de la realidad retratada. Escribiendo a tres voces, sin desvelar en ningún momento la autoría de cada uno de los fragmentos y teniendo como punto de partida un diálogo con las cartas de la monja Mariana Alcoforado, Cartas de Amor de la Monja Portuguesa, las tres Marías encuentran en la monja portuguesa la cómplice perfecta para establecer un diálogo polifónico, al que se irán juntando cada vez más voces.

El título de Nuevas Cartas Portuguesas revela desde el principio una intencionada declaración de principios que, aparte de aludir a la complicidad entre la protagonista setecentista y las modernas, exige una reactualización de la palabra escrita por la monja portuguesa. El trabajo es iniciado por la labor literaria, y social, de las tres Marías, pero perseguirá mediante la lectura, la reflexión y el compromiso de todos los lectores. En Nuevas Cartas Portuguesas deparamos con un proceso de recuperación de la historia de Mariana Alcoforado mediante ese trabajo de reconstitución y de recuperación de los diversos testimonios que nos permitirán establecer una línea de continuidad entre las vivencias de todas las mujeres, independientemente del tiempo o del espacio en que habiten, anónimas o consagradas, siendo la monja portuguesa una de las primeras voces femeninas que se atreve a hacerse escuchar para reclamar a la sociedad un lugar digno para la mujer que vaya más allá del de progenitora y ama de casa, al mismo tiempo que exige su derecho a expresar sus sentimientos y a ser igual de liberal que el hombre, sin que por eso pueda ser condenada o marginada.

Es precisamente a partir de ese juego de reconstrucción que percibimos la verdadera dimensión de las palabras de Elena Losada cuando afirma que "Mariana ya no es Alcoforado" (Losada 2006: 160), ya que es precisamente gracias a las tres Marías que Mariana se libera del linaje paternalista para instaurar su propia genealogía como mujer liberada y liberadora puesto que "sólo en manos de las escritoras Mariana adquirirá una verdadera dimensión mítica" (Losada 2006: 163), por lo que se puede afirmar que con Nuevas Cartas Portuguesas la mujer consigue pisar por primera vez el largo camino de la emancipación social perfilado por la monja portuguesa.

Mariana Alcoforado nació en el seno de una familia popular de Beja, en 1640, donde murió a la edad de 83 años. Su padre se quedó viudo y, de acuerdo con los preceptos sociales de por aquel entonces, para ahorrar la dote que tendría que pagar al futuro yerno, obligó a su hija a ingresar en un convento de clausura. Esta, desinteresada de cualquier inclinación mística, conoció al Conde de Chaumilly quien, según reza la 
leyenda, había venido a Portugal con las tropas de Luis XIV para, en un principio, ayudar a los lusos en la guerra de la independencia contra los castellanos. Sor Mariana conoció entonces la pasión y los goces terrenales con el soldado francés, lo que desencadenó un escándalo social que obligaría a su amado a volver a Francia, pero no sin antes hacerle la promesa de que volvería para rescatarla de la celda del convento. En su eterna espera, ella le escribió cinco cartas con las que la tradición literaria instauró un diálogo que pasa por Bucage, Rousseau, Camilo-Castelo-Branco, Rilke, Ana Hatherley, Adília Lopes, Eugénio de Andrade, Matisse, Mário Botas y otros, como Mário de Cesariny y las tres Marias. Tres siglos más tarde, Mariana Alcoforado constituye el símbolo que representará a todas las Marias o Marianas que configuran una sociedad y que, mediante un juego de heterogeneidades, nos permitirá "desenmascarar" la realidad de una sociedad como la portuguesa, pero que, al final, comulgará con otros espacios, traspasando fronteras geográficas, pero también temporales. Esta complicidad que se establece en Nuevas Cartas Portuguesas es la que nos permite vislumbrar ese juego de máscaras en que se van "desenmascarando" realidades y complicidades. Como ya lo dejamos entrever, la primera connivencia que resalta en este proyecto es precisamente la de la autoría, ya que las tres autoras asumen desde el inicio un texto simultáneamente plural y único; plural en la medida que, escrito a "seis manos", se transformará en la voz de todas cuantas se identifiquen con lo que en estas líneas queda inscrito, y único porque esa diversidad de discursos, de voces y de vivencias confieren al texto una unidad que sirve de refuerzo y cohesión del proyecto inicial, y en el que "personagens também são as autoras que a si mesmas se apresentam" (Pintassilgo 1979: 16). Al final, tras esta polifonía de voces resuena una única voz, la de la mujer que pretende romper los patrones que la sociedad insiste en trazar, y la autoría, de colectiva se convierte en singular y universal.

La complejidad de voces se refleja en el proceso narrativo, pues si Mariana Alcoforado optó por el género epistolar, en Nuevas Cartas Portuguesas la epístola, que la tradición literaria dotó de un perfil más confesional, va más lejos al implicar el diario, como relato de vivencias y sentimientos apoyado por una continuidad cronológica que va de marzo a octubre de 1971. Por otro lado, vemos como la prosa convive aquí con la "poesía lírica y/ o erótica", como lo definen las propias autoras (Barreno et alli 1974: 17). Y, a la par de los poemas de las autoras, podemos encontrarnos aún con otras citaciones de textos de otros autores, voces, identificadas o anónimas, que contribuyen todas ellas a la amplificación de ese discurso polifónico iniciado por las escritoras.

Bajo esos juegos de máscaras, el género epistolar "desenmascara" un proceso creativo innovador y rompedor como subversión de los cánones literarios establecidos por la tradición, al servicio de una nueva realidad que la modernidad tiene el poder de revelar, a medida que avanzamos en la lectura de estas cartas. El "yo" intimista novecenticista es ahora reemplazado por un "yo" colectivo confinado por una vasta estirpe de Marianas y Marías, tías, primas y amigas pero todas ellas hermanas, en un principio de verdadera fraternidad universal. Estas hermanas surgen aquí dispuestas a descubrir la clausura en que viven simplemente por haber nacido mujer, $\mathrm{y}$, sin ninguna duda, esta denuncia es hecha en un tono agresivo y delator hacia los responsables de esta realidad. En un primer y último momento se acusa al hombre de ser el responsable de esta coacción, pero no sin ignorar la pasividad de las madres y hermanas que se convierten en guardianas de los muros del convento en que ellas mismas viven y que urge derribar cuanto antes. Ya le decía Mariana, en un tono desgarrador, a su madre en una de sus cartas: "Sabed, señora madre: nada de lo vuestro me importa, ni pensamientos, ni costumbres." (Barreno et allí 1974: p.71); éste es el grito de renuncia que implica un corte con esas tradiciones y costumbres que insisten en perdurar y que ya no pueden mantenerse en una sociedad moderna. Pero, a pesar de estas voces, las generaciones se suceden y los interrogantes siguen siendo los mismos en lo que a la condición femenina se refiere, por lo que escucharemos desahogos como el de María Ana, nacida en 1800: "¿Qué cambió en la vida de las mujeres?" (Barreno et allí 1974: p.165) pues, tristemente, nada más que "el adorno de los muebles, de las sillas y de los cortinajes" (idem, 165). Tal como se puede leer en las Nuevas Cartas Portuguesas, la mujer es consciente de que, a pesar del paso de los años, su entrega, su responsabilidad y su sacrificio como esposa y madre continúan siendo una amenaza para el descubrimiento de una identidad plena como mujer libre y responsable por sí misma en cuanto individuo. Al final llegaremos a la constatación de que los trescientos años que separan las dos obras son equivalentes a los treinta años que separan la generación de una madre y la de una hija, lo que legitimaría, una vez más, la genealogía establecida por este grupo de mujeres. En el siglo XX, en el trabajo de reconstrucción de las cartas setecentistas, a partir del amor de Mariana por Chaumilly se revisa intencionadamente una sublimación del amor carnal y erótico de la monja, en detrimento de un sentimentalismo líricoromántico, de forma que el discurso adquiera ahora un tono más liberal y agresivo, de denuncia y acusación por lo que, a partir de ese trabajo de reconstrucción de la palabra, legitimado por la literatura, queda patente un fuerte poder de evocación y llamamiento a la reacción de las otras Marias y Marianas que vengan a leer estas Nuevas epístolas.

Por todo esto, no es de extrañar que las Tres Marias manifiesten su compromiso y su ilusión para con esta nueva tarea que tienen entre manos, insinuando: "Pensad, hermanas mías [...] en esta novedad literaria que ha de venderse, os lo aseguro (Barreno et allí 1974: 24)." Esta seguridad es fruto de la conciencia adquirida por nuestras autoras a propósito del estado de letargo en que la sociedad portuguesa ha permanecido, silenciando los ruidos y las voces que se fueron alzando a lo largo del tiempo, por fin ha llegado el momento de usar la palabra para despertar la sociedad. Los tiempos y las sensibilidades han cambiado, siendo ahora necesario emprender 
un trabajo de innovación y adaptación del discurso, de modo que los ruidos sean perceptibles e inteligibles por las hermanas del presente. En consecuencia, son las propias autoras quienes, perfilando los preceptos metodológicos, nos advierten de cómo ética y estética, forma y contenido, voces y palabras, no son más que conceptos que se alían en función de un mismo objetivo concreto y vital.

En este libro, el "qué" no puede separarse del "cómo". Ésta no es la obra de un escritor aislado que se debate durante un tiempo con fantasmas personales o con problemas de expresión a fin de comunicarse con un "otro" abstracto, ni tampoco el resultado de la producción de tres autoras que hayan trabajado de esta forma, por separado, sobre un mismo tema. Este libro es el informe escrito de una experiencia mucho más viva, amplia y real [...] es decir, el resultado de la interacción no sólo de varios modos de escribir sino de varios modos de ser. (Barreno et allí 1974: p.15)

Haciendo gala de este rasgo de modernidad que las traspasa, Nuevas Cartas Portuguesas irrumpen como un rompecabezas donde las piezas, marcadas por su heterogeneidad, trazan un retrato fiel de la realidad, compuesta por varios registros, pero también por distintas sensibilidades. Luego vemos que las autoras evitarán cualquier tipo de sofisma al optar por denunciar a los cuatro vientos la condición de la mujer portuguesa en la segunda mitad del siglo XX, que seguía viviendo en el mismo régimen de clausura que la monja portuguesa del siglo XVII. A pesar de la disparidad diacrónica, el paralelismo sincrónico es bastante evidente. En ambos contextos se manifiesta el poder tutelar de una sociedad que insiste en mantener a la mujer en un sistema castrador y anulador de cualquier instinto de emancipación o liberación. Veamos esta cita de una carta de un novio atribulado al hermano de su novia, y su amigo de infancia, por lo que se entienden a la perfección:

\section{Me calienta la cabeza la mujer, mal rayo que tiene malas pulgas. Está llena de orgullo y tan tozuda como que se le metió en la cabeza que no se casa, "es mejor acabar con todo" y que esto y que lo otro haciéndose la señora porque tiene estudios, y yo ahora ya no le sirvo, que ya le dije a su madre, mi madrina "póngala a coser si es débil de salud, y si nació demasiado fina para el campo. Eso de los estudios no me agrada" (Barreno et allí 1974: p.205)}

¡Qué peligro tienen los estudios para una mujer! ¿verdad? Efectivamente, y eran pocas las mujeres que, en un país de escasos recursos, podían llegar al estado de "conciencia" que denota esta novia. Pero hoy en día es posible que algunos piensen que esta situación constituye un ejemplo que no se corresponde ya con nuestra realidad. En ese caso, creemos que no será difícil establecer el mismo juego analógico que aprendemos a realizar entre la clausura del convento seiscentista y la clausura social del siglo XX. Son aún varios los casos en nuestra sociedad, ya en el siglo XXI, en que la superioridad cultural o económica de la mujer constituye aún una seria amenaza para el honor y reputación del hombre, lo que, siendo así, convendría evitar para que de ahí no surgieran consecuencias negativas para el "buen funcionamiento" del orden social establecido por un patrón clasista y sexista. Siguiendo ese juego analógico, vamos testimoniando nuevas situaciones cotidianas que urge denunciar, como la de esta pobre jornalera:

Mi destino fue ser infeliz, no vale la pena luchar contra él, señora, no vale la pena, el hombre puede rebelarse siempre que quiera pero la mujer está atada a él, y si no a los hijos, ¿y después? Incluso mi Antonio en el fondo tampoco es malo, no señora, y ademas es el padre de mi Antoñito, pobre criatura...(Barreno et allí 1974: p.191)

Posiblemente no nos cueste tanto vislumbrar en este caso la sinopsis de uno de los innumerables contextos familiares en que tienen lugar algunos de los casos de violencia de género que invaden nuestra cotidianeidad. La sumisión y el conformismo en que la mujer vive encerrada hará que, al final, ella siempre esté dispuesta a entender y a asumir el perdón de su verdugo y, conscientes de esta realidad, a nosotros lectores no nos pasa desapercibida esa continuidad generacional que se presagia en la repetición del nombre delhijo, advirtiéndonos delanecesidad urgente de actuar para quelos ciclosnose repitan. Paralelamente al deseo de provocación de las mentalidades portuguesas, por detrás del proyecto emprendido por las tres autoras existe una confianza en esos nuevos vientos que empiezan a mover la sociedad y las nuevas generaciones, pero hay que mantener firme la actitud de vigilia. En este sentido las autoras alertan del hecho de que la mujer sigue siendo la victima de un sistema polifacético, y que puede estar representado por realidades distintas como sean la religión, la familia o la política, pero también por un cambio en el sector económico de una sociedad que empezaba entonces a dar sus primeros pasos en la era industrial.

A inicios de los años setenta la situación político económica de Portugal obligó a que los hombres partieran en grandes contingentes hacia la guerra en África o emigraran en busca de un sustento para la familia. En los grandes centros urbanos se empieza a demandar la mano de obra femenina, la cual proviene en gran mayoría de las zonas rurales, y esa mujer que aprendiera a ser una buena esposa, una buena ama de casa y una buena madre, se siente doblemente defraudada ya que, además de tener que trabajar en algo para lo que no había sido "enseñada" y que acumula a sus tareas femeninas, es cada vez más explotada y menos gratificada, asomando peligros desde nuevas perspectivas:

Cuando se lee o se oye decir: “La mujer hoy en día trabaja ya en los más variados sectores de la produch ad hay que entender lo siguiente: la mujer hoy en día va siendo utilizada en los sectores de la producción en las profesiones, en las funciones que los hombres rechazan ya, por malas condiciones de trabajo y de remuneración. (Barreno et allí 1974: p.231) 
En ese ciclo que el progreso instaura la mujer sigue siendo el elemento más débil explotada laboralmente dentro y fuera del hogar, una vez que se le seguirá exigiendo que cumpla, además del trabajo remunerado, con los deberes de SU hogar y de SU familia. Por otra parte, a la mujer le acecha aún otro peligro, como es el de ser utilizada por una cadena progresista por cuyo engranaje terminará siendo engullida puesto que "de objeto productor de hijos y de trabajo doméstico, pasó también a objeto consumidor y de consumo; antes era como una propiedad rural, para ser fecunda, y ahora está comercializada, para ser distribuida." (Barreno et allí 1974: p.232) Este es el progreso que espera a las mujeres por lo que, como si de un grito profundo se tratara, las autoras expresan vehementemente la ira que sienten, denunciando explícitamente un texto de la época en el que se afirmaba que "la mujer es la última colonia del hombre" (Barreno et allí 1974: p.249). Rechazada cualquier ironía hay que reflexionar e intervenir de inmediato contra la utilización de la mujer, como si de un simple recurso economicista y capitalista se tratara, y donde el hombre es cómplice.

Y el hombre se alboroza, hermanas, y ayuda a la mujer en esta farsa, en esta trampa, en esta falsa y vergonzosa "liberación" en la que la mujer está cada vez más aprisionada (y ahora de si misma), más enredada en las mallas de una sociedad que a utiliza, la domina, la esclaviza, la conduce, la manipula, la consume . (Barreno et allí 1974: p.249)

En el contexto social portugués de los años 70, esta nueva situación de esclavitud adquiere una importancia vital, sin que sea posible ignorar la interferencia de los restantes contextos inherentes a una educación tradicional. En un momento en que la sociedad empieza a reaccionar y los movimientos cívicos intentan hacer frente al régimen, desafiando el clima de miedo que se había instalado a lo largo de décadas, la censura portuguesa ha visto en estas cartas otros factores de desestabilización social además de los moralistas peros, siempre bajo la máscara de perversas y obscenas. La naturalidad con que la realidad cotidiana de la mujer es retratada puede ser bastante incómoda y hacer despertar algunas sensibilidades, por lo que es por demás evidente el juego de denuncia que aquí se hace de una situación política que el régimen conducía paso a paso hacia el abismo.

Gracias a la política del "orgullosamente solos" seguida por Salazar, Portugal se tornó un país cada vez más cerrado en sí mismo, sin posibilidad de crecer económica o socialmente. La única expansión que conocíamos era la ultramarina, donde residía el sueño colonial del que el régimen no quería abdicar, a pesar de las sucesivas advertencias de los máximos organismos internacionales, como la ONU. Ese sueño acabaría por ser alimentado, por un lado, con gran parte del dinero del estado, y por otro con los hombres, padres e hijos, que partían para África para cumplir con el deber militar. Como alternativa restaba la posibilidad de "dar el salto", o sea, pasar clandestinamente la frontera para emigrar para Francia, Suiza, Alemania o Canadá Los padres de familia o hijos en edad de trabajar partían como clandestinos, y como tal vivían en esas ciudades donde trabajaban a lo largo de largas y duras jornadas, sin contactos con las poblaciones locales y privados de un vínculo familiar, ya que la única responsabilidad que tenían se limitaba a enviar dinero a casa. En Portugal se dibujaba un retrato en blanco y negro de mujeres sin maridos, de novias sin novios, de hijos sin padres. $Y$, una vez más, es la mujer la que se tiene que sacrificarse, olvidándose de ella misma. Con escasa instrucción, o incluso analfabeta y desamparada, luchará arduamente por mantener la casa y la "unidad familiar" por lo que se convierte fácilmente en un elemento privilegiado de explotación social.

En este contexto, la responsabilidad sobre la educación de los hijos y la economía familiar es de su entera responsabilidad. Encima, la mujer tiene que estar preparada psicológicamente para el hecho de poder perder a su marido, a su novio o a su hijo, o peor, recibirlo en su casa, una vez destrozado física y psicológicamente por las desdichas de la guerra, "inhábil" para cualquier trabajo:

\section{Él está en el hospital con una pierna de menos y no sé lo que va a ser de él cuando regrese a Carvalhal pues para el trabajo de la tierra se echa de menos y él no sabe hacer otra cosa [...] El padre del Francisco ya le escribió del Canadá donde está emigrado contándole que por alla no hay vida para mutilados, que se las arregle junto a su madre de cualquier manera y el pobre ni acabó de leer la carta y la rompió delante de mí cuando lo fui a visitar al hospital para darle ánimos al pobre hombre allí olvidado a vueltas con su disgusto. (Barreno et allí 1974: pp.246-7)}

Junto con el dramatismo que se respira en pasajes como el que acabamos de leer donde el desarraigo familiar es bastante evidente, entrevemos el estado en que la mujer se encuentra, educando sola a sus hijos, cargando sola el peso y la responsabilidad de toda la familia y padeciendo las angustias de la vida en la más absoluta y pesada soledad:

Y como recuerdo sólo tengo el cariño que me diste hace ya dos años por marzo y parecíamos novios y arreglados [...] y quién sabe si me echas a perder pues yo no te quiero de vuelta para verme las caras y la ruina de vieja y los modales de viuda rica gracias a ti. (Barreno et allí 1974: p.129)

Viviendo en el dolor y en la ausencia como viudas, pero de un marido vivo, la mujer ve sacrificada su relación familiar, el cariño y el amor matrimonial, por un compromiso material a modo de poder educar a sus hijos, pero sin conseguir ningún tipo de independencia o autonomía, más bien todo lo contrario. Además de sufrir la falta de cariño y de amparo conyugal, la mujer es cada vez más vigilada por una sociedad que exige de ella que sea siempre una señora de buenos modales, con un comportamiento digno del nombre de la familia del marido que, aunque lejos, es el 
que sigue estableciendo las normas de conducta del hogar familiar en que él no vive. Este contexto provocará que la mujer sea víctima, una vez más, de una perspectiva reductora que la concibe en dos únicas imágenes antagónicas; la mujer honrada, devota y fiel a su amo, aunque éste se mantenga ausente, o la mujer de mala conducta, liberal y libertina, tentadora y embaucadora; o sea que nos encontramos de nuevo con una dualidad tradicional que nos enseñó a interpretar la mujer como angelical o demoníaca y, una vez más, la voz de las tres Marías se alza contra esta visión reductora.

En la batalla aquí emprendida es evidente el empeño en la lucha contra una sociedad que fue alimentando una serie de componentes que tenían como objetivo forjar una mujer sobre todo compañera y protectora "porque en la sociedad, y por ella, la mujer es asexuada" (Barreno et allí 1974: p.102). En tiempos deguerra, la figura dela madrina de guerra cumple a la perfecciónese modelo por lo que no podía faltar en esta vasta galería de cuadros sociales que Nuevas Cartas Portuguesas nos van proporcionando. Las chicas aceptaban mantener correspondencia con un joven que estuviera cumpliendo el servicio militar en África. Al no ser viable la posibilidad de mantener un contacto físico, a la chica le cabe el papel de aliviar la soledad y las amarguras del destierro, enviando por correspondencia su apoyo, cariño y hasta amistad, sin que sea legítimo que ésta tenga alguna expectativa que vaya más allá de un compromiso circunstancial de modo y de tiempo.

Como venimos observando, gracias a la habilidad de las autoras, la diversidad de estilos y discursos narrativos permite la introducción de múltiples cuadros de la realidad que consienten el cruce simultáneo de distintas perspectivas de una misma sociedad y así es como en Nuevas Cartas Portuguesas vamos reconstruyendo un retrato del paisaje humano, pero también natural, íntimamente relacionado con la situación de la mujer. De igual forma que la mujer que aquí encontramos perdió ya la carga lírico-romántica transmitida por patrones clásicos, para asumir un tono de irreverencia y rebeldía, también el medio rural surge despojado de cualquier bucolismo, en detrimento de una significativa denuncia del precio que el progreso impone; la armonía vital y natural es ahora anulada por la fuerza artificial y destructiva de la industria, pero también por la guerra dado que, si la polución de las fábricas contamina los ríos y las tierras, también aquella contagiará la vida de las gentes. Junto con lo anteriormente apuntado, la falta de apoyos económicos y la escasez de mano de obra masculina inducen a un abandono generalizado de las poblaciones rurales hacia los grandes centros urbanos. Gran parte de este colectivo son mujeres que, impelidas a buscar el sustento de los abuelos, padres o hermanos, son también ellas victimas del desarraigo y soledad que viven sus padres, hermanos o maridos en ese mundo de afuera. La mujer es entonces obligada a vivir en una realidad donde todo es artificial, y donde ella se siente desamparada, en la profunda soledad que sólo una ciudad es capaz de albergar. Una vez más, como emigrante dentro de su país, a la mujer se le exige lo mismo que al hombre, pero sin que a ella le esté permitido conquistar la autonomía o emancipación que tenían los hombres fuera de su casa; al revés, la mujer, subyugada a las leyes de esa sociedad profundamente sexista, es permanentemente vigilada por todos. Y este progreso conllevará aún más costes, y no sólo para la mujer o la economía, sino también para la naturaleza. En un país sin infraestructuras ni una razón cívica desarrolladas, la madre naturaleza es igual de desvalorizada y usada que la mujer, lo que denota en este texto un compromiso ecologista que, medio siglo después, sigue siendo igual de oportuno. Veamos el testimonio aportado por esta mujer de la pequeña aldea del Carvalhal representativa de tantas otras aldeas de Portugal:

Por culpa de las sucias aguas del Caima que ya viste lo echan todo a perder y de los peces y las judías ni hablar y así todos los gastos no sirven de nada, por culpa de la fábrica de papel que aún es lo que da trabajo a los que se quedan aquí hasta que llega el servicio militar [...] El pescado anda todo muerto por el Caima abajo y ni la ropa se puede enjuagar allí por culpa del olor que ni los animales se acercan a beberla. (Barreno et allí 1974: pp.127-128)

En los inicios de los años 70 el ruido provocado por esas voces marca efectivamente un punto de inflexión, pero el trabajo es largo y será difícil luchar contra una tradición que insiste en desarrollar reglas de conducta alimentadas por tradiciones y costumbres sociales difíciles de derribar. A pesar del trabajo realizado, sobre todo en las últimas décadas, hay mucho trabajo por delante residiendo el valor de estas autoras en la tenacidad y fuerza con que adaptaran modelos y recursos para que, al mismo tiempo que se genera una compasión hacia los valores heredados de nuestras madres, $y$, en un acto de coraje, romper definitivamente con ellos porque, como se puede leer en las Nuevas Cartas Portuguesas "el problema de la mujer, en medio de todo esto, no es el de perder o ganar: es el de su identidad". (Barreno et allí 1974: p.250)

A partir de este momento, teniendo en cuenta la intertextualidad entre las cartas de Mariana Alcoforado y las de las tres Marias, es inevitable dejar de establecer el paralelismo entre la vida de clausura de la monja portuguesa y la de las mujeres del siglo XX, los muros son ahora los de la sociedad, vigilante e implacable para con la mujer enclaustrada en su casa, por su familia y por todos cuanto la vigilan. Las palabra de los dos discursos, separados por tres siglos, instauran un diálogo perfecto donde, a partir de una profunda complicidad, al mismo tiempo que se pone en evidencia la falsa moral de una sociedad hipócrita, se defiende una sociedad donde la mujer pueda tener la libertad de decidir sobre su destino, sus sentimientos, sus deseos y su cuerpo, como ser racional que es. Podríamos entonces decir que, junto con la lucha feminista, la reivindicación que subyace en este discurso es sobre todo humanista, exigiendo para la mujer una dignidad y un estatus social que le permita competir en igualdad de condiciones que el hombre. 
En este sentido, bajo la máscara de la igualdad femenina, parece evidente que la denuncia va más allá, puesto que lo que aquí se denuncia es a la política cruel del régimen que no hacía más que desestructurar cualquier posibilidad de que se estableciera un sistema social en que mujeres y hombres tuvieran los mismos derechos, oportunidades y deberes. Será sin duda una de las razones para que la obra y sus autoras sean objeto de censura y pena criminal. Si alguna duda nos resta, podemos recoger la advertencia hecha por las autoras a propósito del papel de la literatura en esta lucha:

\section{¿Qué puede la literatura, hermanas, las palabras, contra todo esto? Teniendo aún que contar con el hecho de que "la mujer no tiene una cultura propia. Existe en una cultura en la que el poder pertenece a los hombres, luego ella está, en esa cultura, alienada"... (Barreno et allí 1974: p.250)}

Esta cita se inicia con una interrogativa sin respuesta, pero luego veremos que es de la incumbencia de las demás hermanas, ya implicadas en el texto, contestar. Al dejar el espacio abierto, marcado por los puntos suspensivos, las autoras pretenden hacer partícipes de esta lucha de la palabra a las demás hermanas que están al otro lado del texto. Efectivamente, la consistencia y la fuerza del discurso de estas tres mujeres supo congregar a muchas voces que, poco a poco, fueron rellenando estos puntos suspensivos, reclamando su derecho a elegir libremente sus decisiones y a expresar públicamente sus sentimientos, sensaciones y emociones sin miedo a ningún tipo de represalia. Pero, llegados a este punto, todos los que hemos asumido la fuerza transmitida por el texto de las tres Marías nos preguntamos si realmente éste mereció ser tildado de obsceno y condenado por pornográfico. Tal y como ya hemos delineado anteriormente, la "indecencia" del texto no está tanto en los caracteres impresos, sino más bien en la fuerza de la palabra; la obscenidad no está tanto en la inscripción de una palabra malsonante o la descripción de un acto de intimidad sexual, independientemente de la condición de cada una, como en el coraje de denunciar los verdaderos pecados de la sociedad. Bajo esa máscara de libertinaje, las autoras consiguieron convocar otras miradas y otras voces, capaces de gritar por el derecho de la mujer a usar su cuerpo y a decidir libremente sobre él, el derecho a decidir sobre si usar su cuerpo para ser madre o no, el derecho a poder trabajar fuera de casa sin los amarres maternales y domésticos, a decidir en igualdad de condiciones que el hombre. En realidad el proceso instaurado por las autoras es simplemente una máscara que no pretendía sino esconder el hecho de que la pornografía reside en la incongruencia de un estado que encarcelaba a una mujer por abortar, mientras, bajo la coacción de ese mismo estado, se destruían incontables vidas humanas en África, en un estado que impone la fe cristiana obligando a sus hombres a incumplir el primer mandamiento; que la indecencia existe en un estado defensor de los valores patrióticos, pero que fuerza sus hombres a la huida clandestina y miserable del país para que puedan alcanzar el sustento de su familia; que la obscenidad está en la contradicción entre un estado defensor de un modelo de sociedad familiar y patriarcal, pero que quita el padre a los hijos y el marido a las mujeres. En todo este elenco de situaciones reside la verdadera pornografía de Nuevas Cartas Portuguesas, por supuesto que con el añadido de haber sido redactadas por tentadoras y maliciosas manos femeninas, capaces de seducir a un auditorio encerrado en el obscurantismo, lo que las hacía extremadamente peligrosas y obligaba a actuar con las medidas más radicales de que el estado disponía, la censura y la cárcel.

Indudablemente, la fuerza de la palabra de las tres Marias tuvo tal poder de convocatoria que ha sabido mantener su vigor a lo largo de estas décadas, lo que hace que esta obra siga siendo hoy un marco en el ámbito de los estudios feministas, por lo que este texto marca, aún hoy, un perfil de modernidad cuyos trazos se han tornado cada vez más nítidos, a pesar del paso del tiempo y de los vientos de mudanza. Hoy en día siguen existiendo fuertes razones para reclamar la lectura de estas cartas como un texto de señalada importancia para la historia de la literatura portuguesa, y de los estudios sobre literatura femenina. El hábil dominio del lenguaje, la habilidad narrativa y la dinámica del discurso permiten que este texto siga "desenmascarando" realidades que insisten en perdurar bajo la máscara de cánones tradicionales ya ultrapasados y, en este sentido, Camões no diría que se han mudado los tiempos, se han mudado las voluntades. A pesar de los cambios producidos, creemos que, en un ámbito público y oficial la sociedad fue debilitando la rigidez de esos modelos espartanos que tallaran entonces el papel de la mujer en la sociedad, pero, en contrapartida, en el espacio de lo privado la mujer no pudo conquistar su liberación al mismo ritmo.

Si el estado y la ley luchan por la instauración de una igualdad de condiciones entre mujeres y hombres, en el espacio privado de la mujer se espera aún que sepa ser esa buena esposa, ama de casa y madre, sin espacio para cualquier tipo de despenalización. Hoy en día, la lucha de las Marias y Marianas no pasa ya por reclamar el indulto legal, sino el respecto de la sociedad por su trabajo y sus tomas de decisión, ya que el estado ha sabido evolucionar mucho más que la familia y el contexto particular y concreto en que la mujer se insiere, el de sus vecinos, sus compañeros de trabajo y hasta sus amigos.

Por todo esto, no nos resta sino concluir que el diálogo entablado en Nuevas Cartas Portuguesas no ha perdido ni un ápice de actualidad, no sólo por el hecho de que haya aún mucho trabajo que hacer en el campo de la igualdad de géneros, sino además, según nuestra opinión, porque la capacidad de focalización y el ingenio literario patentes en la obra son de una extrema modernidad, inspirada en Mariana Alcoforado. El grito de coraje y valentía lanzado por la monja portuguesa en el siglo XVI fue capaz de invocar el valor y la audacia de las tres Marias y a nosotras nos incumbe mantener y dinamizar 
ese mensaje ya que, junto con la reivindicación feminista existe un trasfondo humanista que la sociedad tiene que percibir y proteger.

\section{REFERENCIAS BIBLIOGRÁFICAS}

Alcoforado, M., Novas Cartas Portuguesas, Lisboa, Ed. Futura, 1974.

-----, Nouvelles Lettres Portugaises, Trad. De Vera Alves da Nóbrega, Eveline le Carreo y Monique Wittig, Paris, Seuil, 1974.

----, Nuevas Cartas Portuguesas, Barcelona, Ediciones Grijalbo, 1976.

----, Cartas Portuguesas atribuidas a Mariana Alcoforado, trad. de Eugénio de Andrade, Edição bilingue, Lisboa, RTP, 1980.

Losada, E., "Mariana ya no es Alcoforado: variaciones, subversiones y parodias en Novas Cartas Portuguesas y en la poesía de Adília Lopes," Asociación de Lusitanistas del Estado Español - I Congreso A.L.E.E. , 206, pp.160-172.

Pintassilgo, M. de L., "Pré - Prefácio e Prefácio a Novas Cartas Portuguesas", Barreno et Alii, Novas Cartas Portuguesas, Lisboa, Moraes Editora, 1980. 